\title{
INTOXICAÇÃO PELO CHUMBO EM PACIENTE COM PROJÉTIL DE ARMA DE FOGO ALOJADO NA CABEÇA FEMORAL
}

\author{
LEAD POISONING IN A PATIENT WITH A FIREARM PROJECTILE \\ HOSTED IN THE FEMORAL HEAD
}

Priscila Pinto Barroso ${ }^{1}$, Altamir de Almeida Filho² ${ }^{2}$ Caio Guimarães Araújo ${ }^{3}$, Camila Pedruzze Machado ${ }^{1}$, Renata Xavier Frechiani de Castro Bergamin ${ }^{4}$, Síbia Soraya Marcondes ${ }^{5}$

${ }^{1}$ Residente de Dermatologia, Serviço de Dermatologia do Hospital da Santa Casa de Misericórdia de Vitória; Vitória-ES, Brasil.

${ }^{2}$ Residente de Hematologia, Serviço de Hematologia do Hospital Santa Marcelina; São Paulo-SP, Brasil.

${ }^{3}$ Especialista em Clínica Médica pelo Hospital da Santa de Misericórdia de Vitória; Vitória-ES, Brasil.

${ }^{4}$ Especialista em Endocrinologia pela Escola Paulista de Medicina (UNIFESP); São Paulo-SP, Brasil.

${ }^{5}$ Professor adjunto do departamento de Hematologia do Hospital da Santa Casa de Misericórdia de Vitória; Vitória-ES, Brasil.

Instituição na qual o trabalho foi realizado/ está vinculado: Irmandade da Santa Casa de Misericórdia de Vitória Comitê de Ética em Pesquisa da Escola de Ciências da Saúde-EMESCAM (CEP/EMESCAM), telefone (27) 33343586, e-mail comite.etica@emescam.br, endereço: Av. N. S. da Penha, 2190, Santa Luiza - Vitória - ES - 29045402.

Autor correspondente: Priscila Pinto Barroso, telefone (27)992042275, e-mail: priscilapbarroso@gmail.com, endereço: R. Ludwik Macal, n 537, apto 301, Jardim da Penha, Vitória - ES, CEP 29060-030.

\section{RESUMO}

Introdução: O chumbo é um elemento tóxico quando na corrente sanguínea, comprometendo os sistemas nervoso, hematológico e renal, além de causar distúrbios gastrointestinais, hipertensão e infertilidade. Os principais meios de exposição são inalação e ingestão, podendo ocorrer na retenção de projétil de arma de fogo em contato com líquido sinovial ou cefalorraquidiano. $O$ tratamento desses casos requer terapia com quelantes do chumbo, além de retirada cirúrgica do projétil. 0 diagnóstico pode ser confirmado por dosagem sérica do metal ou ácido delta-aminolevulínico (ALA) no sangue ou urina, protoporfirina de zinco ou protoporfirina livre.

Objetivos: Relatar um caso de intoxicação pelo chumbo secundário à retenção de projétil de arma de fogo; Auxiliar no reconhecimento da doença; Discutir sobre o tratamento e seguimento da doença; Auxiliar no manejo clínico de casos semelhantes.

Descrição do caso: paciente de 25 anos, pintor, vítima de 3 acidentes com projétil de arma de fogo,

\section{ABSTRACT}

Introduction: Lead is a toxic element when in the bloodstream, compromising the nervous, hematological and renal systems, in addition to causing gastrointestinal disorders, hypertension and infertility. The main means of exposure are inhalation and ingestion, but it can also occur in the retention of a firearm projectile in contact with synovial or cerebrospinal fluid. The treatment of these cases requires the use of lead chelators, in addition to surgical removal of the projectile. The diagnosis can be confirmed by serum measurement of lead or delta-aminolevulinic acid (ALA) in blood or urine, zinc protoporphyrin or free protoporphyrin.

Objectives: To report a case of lead poisoning secondary to the retention of a firearm projectile; Assist in the recognition of the disease; Discuss the treatment and follow-up; Assist in the clinical management of similar cases.

Case Report: 25-year-old painter, victim of 3 accidents with firearm projectiles, had 1 projectile lodged in the proximal region of the left femur, in contact with synovial fluid. After 4 years, he 
possuía 1 projétil alojado na região proximal do fêmur esquerdo, em contato com líquido sinovial. Após 4 anos, evoluiu com sintomas de intoxicação por chumbo (dor abdominal, anemia, crise convulsiva e disartria), confirmação diagnóstica através da dosagem sérica de $226,7 \mathrm{mcg} / \mathrm{dL}$ (valor de referência $40 \mathrm{mcg} / \mathrm{dl}$ ). Realizado tratamento com quelante do chumbo e artroplastia do quadril, com melhora completa dos sintomas.

Conclusões: casos de intoxicação podem gerar sinais e sintomas inespecíficos. Portanto, se torna importante a educação dos profissionais de saúde acerca do tema, para correto diagnóstico e manejo destes pacientes.

Palavras-chave: Intoxicação por chumbo.

\section{INTRODUÇÃO}

O chumbo é um elemento tóxico do meio ambiente que leva a grandes complicações ao entrar na corrente sanguínea, afetando múltiplos órgãos e sistemas. ${ }^{1}$

Os principais meios de exposição ao chumbo são inalação e ingestão. O metal é veiculado por partículas suspensas no ar liberadas por veículos movidos à gasolina, tintas com base de chumbo, brinquedos pintados ou que possuam o chumbo como matéria prima, alimentos e água contaminada, além da exposição ocupacional principalmente nos setores de fabricação, construção civil e mineração. A maior aplicação atual do chumbo é na criação de baterias para automóveis, computadores, equipamentos de telecomunicações, energia solar e eólica. ${ }^{2}$

A apresentação clínica da intoxicação por chumbo envolve comprometimento dos sistemas nervoso, hematológico e renal, mas também pode levar a distúrbios gastrointestinais (anorexia, vômito, constipação, dor abdominal), hipertensão e comprometimento da fertilidade. ${ }^{1}$

Os sintomas neurológicos incluem ataxia, estupor, coma, convulsões, hiperirritabilidade, Q। reduzido, déficit de atenção, aumento do comportamento anti-social, desempenho escolar reduzido e até morte. O comprometimento do sistema hematológico pode envolver a interrupção da síntese de hemoglobina ou hemólise, levando à anemia e seus sinais clínicos específicos, como fraqueza e fadiga. Os efeitos do chumbo no sistema renal consistem em comprometimento da função developed symptoms of lead poisoning (abdominal pain, anemia, seizure and dysarthria), diagnostic confirmation by means of a serum dose of $226.7 \mathrm{mcg}$ / dL (reference $40 \mathrm{mcg} / \mathrm{dl}$ ).Treatment with lead chelation and hip arthroplasty was performed, with complete improvement of symptoms.

Conclusions: cases of lead intoxication can generate nonspecific signs and symptoms. Therefore, it is important to educate health care professionals on the subject, for the correct diagnosis and management of these patients.

Keywords: Lead poisoning. Gunshot wounds. Synovial fluid.

tubular proximal, levando a aminoacidúria, glicosúria e hiperfosfatúria, nefrite intersticial na exposição crônica e comprometimento do metabolismo do cálcio. ${ }^{1}$

O diagnóstico pode ser confirmado por dosagem do chumbo sérico ou por parâmetros indiretos de seu efeito na síntese de hemoglobina, como ácido delta-aminolevulínico (ALA) no sangue ou na urina, protoporfirina de zinco ou protoporfirina livre. ${ }^{3}$

Madureira PR et al descreveram em 2009 que a intoxicação pelo chumbo pode ocorrer em situações especiais, como nos casos de retenção de projétil de arma de fogo em contato com líquido sinovial ou líquido cefalorraquidiano, visto que o ph ácido desses fluidos causa solubilização do chumbo e absorção plasmática do mesmo. O tratamento desses casos requer terapia com quelantes do chumbo, além de retirada cirúrgica do projétil de arma de fogo como tratamento definitivo. ${ }^{3}$

Os agentes quelantes disponíveis atualmente incluem: ácido 2,3-dimercaptosuccínico (DMSA), dimercaprol, ácido etileno diamina tetraacético (CaNa2EDTA) e D-penicilamina. ${ }^{1}$

Neste trabalho relatamos o caso de um paciente com intoxicação por chumbo devido a projétil de arma de fogo retido na região proximal do fêmur esquerdo, em contato com líquido sinovial.

\section{OBJETIVOS}

Relatar um caso de intoxicação pelo chumbo secundário à retenção de projétil de arma de fogo; Contribuir com a literatura científica no 
reconhecimento da doença; Discutir sobre o tratamento e seguimento da doença; Auxiliar no manejo clínico de casos semelhantes.

\section{DESCRIÇÃO DO CASO}

Paciente masculino, 25 anos, pintor há 2 anos, vítima de 3 acidentes com projétil de arma de fogo (PAF), possuía 1 projétil alojado na região proximal do fêmur esquerdo há 5 anos. Evoluiu 4 anos após o acidente, em 2017 e 2018 com episódios de dor abdominal intensa que o levaram ao pronto socorro por 3 vezes, necessitando de internação em um episódio, quando apresentou também crise convulsiva, apesar de história negativa de epilepsia ou outras comorbidades. Nesta internação, foi avaliado por hematologista devido a anemia e diagnosticado com alfatalassemia.

Em consulta de seguimento da anemia microcítica e hipocrômica apresentou VDRL reagente $1 / 16$, FTA-ABS IgM reagente e relato pela acompanhante de alteração neurológica (disartria) há cerca de 8 meses, sendo encaminhado para internação hospitalar e investigação de neurossífilis.

Durante a internação foi aventada hipótese diagnóstica de intoxicação pelo chumbo devido à exposição ocupacional do paciente (pintor), além da presença de projétil de arma de fogo alojado em coxa esquerda e como fator causal para a anemia, sintomas gastrointestinais e neurológicos.

Ao exame físico apresentava linha gengival de Burton (Figura 1), uma linha cinza ao longo da margem gengival, sinal de intoxicação crônica por chumbo que se desenvolve quando o metal reage com os metabólitos de bactérias orais, o que corroborou com a hipótese. Solicitada a dosagem sérica do chumbo e prosseguida investigação da anemia (hemoglobina de 6,1 em 05/07/2018) e da hipótese de neurossífilis.

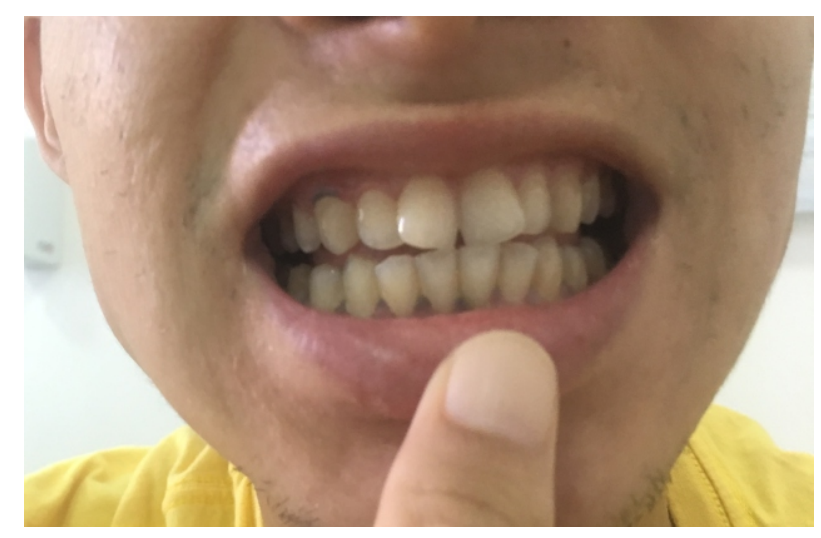

Realizou tomografia computadorizada do crânio, sem alterações significativas e punção lombar com VDRL não reagente no líquor. Realizado tratamento para sífilis indeterminada com 3 doses semanais de Penicilina G Benzatina 2,4 mi UI.

Realizadas também radiografia do abdome, sem alterações e radiografia da articulação coxofemoral esquerda que demonstrou a presença de projétil de arma de fogo alojado na cabeça femoral esquerda e cápsula articular calcificada denominada Bursogram (Figura 2).

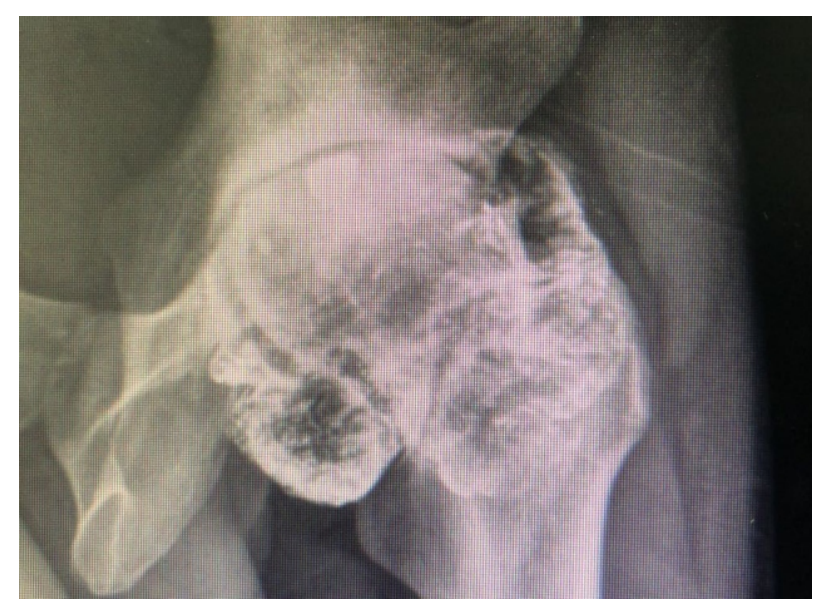

Após dosagem sérica de Chumbo com valor $197,2 \mathrm{mcg} / \mathrm{dL}$, sendo a referência $40 \mathrm{mcg} / \mathrm{dL}$, confirmando níveis de intoxicação, foi realizado contato para orientações com o centro de intoxicação do ES (TOXCEN) e o centro de referência para intoxicação pelo Chumbo (CIATOXCAMPINAS/SP). Nova dosagem sérica confirmatória com valor $226,7 \mathrm{mcg} / \mathrm{dL}$ (16/07/18), dosagem de porfobilinogênio negativa e ALA-Urinário "maior que 12 " $\mathrm{mg} / \mathrm{g} \mathrm{Cr}$, sendo o valor de referência até 4,5 $\mathrm{mg} / \mathrm{g}$ Cr ou pelo IMBP até $10 \mathrm{mg} / \mathrm{g} \mathrm{Cr}$.

O projétil alojado na cabeça femoral esquerda formou uma cápsula articular calcificada pelo chumbo denominada "Bursogram", sendo necessária artroplastia do quadril, com colocação prótese articular e retirada da cápsula articular, visto que a retirada apenas do projétil não resolveria o quadro de intoxicação.

Em avaliação da equipe de ortopedia foi solicitada tomografia computadorizada do quadril, que demonstrou sinais de coxartrose no quadril esquerdo, com calcificações em topografia da cápsula sinovial adjacente à cabeça e colo femoral, e presença de fragmentos de PAF na região da cabeça femoral e acetábulo esquerdos. 
Além do tratamento cirúrgico, foi indicado uso de medicação quelante do chumbo intravenosa (ácido etileno diamina tetra-acético - CaNa2EDTA), realizada por 3 dias.

Abordagem cirúrgica realizada em agosto/18 com artroplastia total primária de quadril esquerdo não cimentada, além de ressecção da cápsula articular acometida pela impregnação por chumbo, bem como retirada de corpo estranho metálico localizado na cabeça femoral (Figura 3).

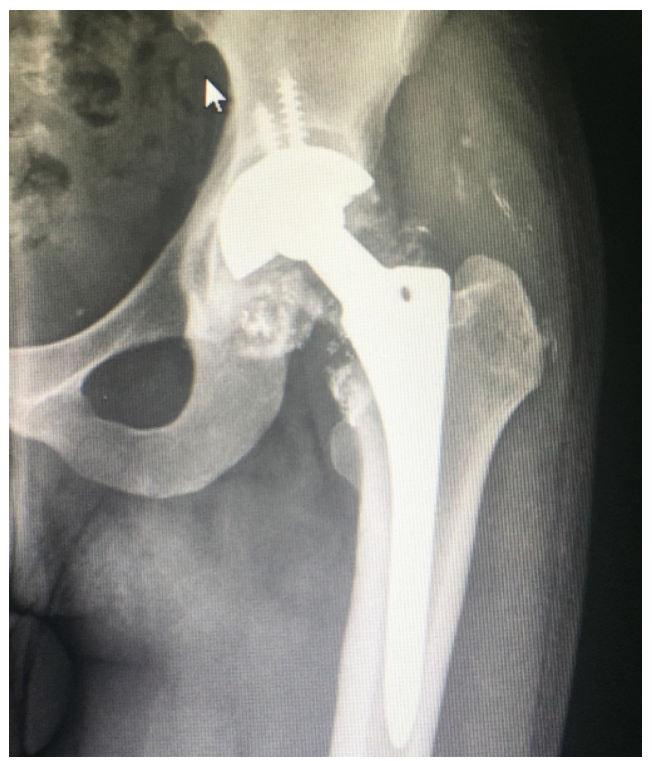

Após tratamento quelante do chumbo e artroplastia do quadril, o paciente apresentou melhora dos sintomas neurológicos e gastrointestinais, sem outras queixas no momento da alta hospitalar.

Em seguimento, novas dosagens de chumbo sérico em 27/08/18 com redução do valor para $120,7 \mathrm{mcg} / \mathrm{dL}$, e ALA-U com redução para 10,2 $\mathrm{mg} / \mathrm{gCr}$.

Em 10/10/2018 dosagem do chumbo sérico $128,5 \mathrm{mcg} / \mathrm{dL}$, ALA-U com redução para $8,5 \mathrm{mg} / \mathrm{g} \mathrm{Cr}$. Após busca ativa, o paciente compareceu a consulta em 30/05/19, neste momento se mantinha assintomático e trouxe exame laboratorial de 12/02/19 com dosagem de chumbo sérico de 84,17 $\mathrm{mcg} / \mathrm{dL}$ e ALA-U $1,53 \mathrm{mg} / \mathrm{g}$ Cr. Neste momento sem indicação de tratamentos complementares.

\section{DISCUSSÃO}

Nos Estados Unidos, Dignam et al demonstraram que a exposição ao chumbo vem diminuindo de 1970 a 2017. Tal pesquisa revelou que no fim da década de $70,78 \%$ da população de 1 a 74 anos tinham níveis séricos de chumbo maiores do que $10 \mathrm{mcg} / \mathrm{ml}$. Em contrapartida, como resultado de regulamentações federais e ações de saúde pública aplicadas para controle de fontes e emissão de metais pesados, de 2015 a 2016 foi estimado que a concentração sanguínea de chumbo na população com a mesma faixa etária anteriormente citada se tratava de $0.82 \mathrm{mcg} / \mathrm{ml}$, representando uma queda de $93.6 \% .^{2}$

Em 2015 o Institute for Occupational Safety and Health designou o limite de chumbo plasmático em $5 \mathrm{mcg} / \mathrm{dL}$ em adultos. ${ }^{2} \mathrm{O}$ que indica um limiar seguro muito baixo, necessitando maior controle de fontes deste metal.

A exposição ocupacional ao chumbo é a causa mais comum de intoxicação, mas projéteis de arma de fogo devem ser pensados como uma possível fonte quando em contato com líquido sinovial ou líquido cefalorraquidiano. No caso de grandes articulações, como quadris e ombros, os pacientes não devem perder o seguimento após os primeiros cuidados de emergência, e os médicos devem planejar a excisão precoce do projétil, para evitar o risco de dissolução tardia e intoxicação clínica crônica por chumbo. 0 grande número de pacientes com projétil alojado reforça a importância deste diagnóstico. ${ }^{4}$

A cirurgia geralmente promove tratamento preventivo e também definitivo. ${ }^{3} \mathrm{Em}$ associação com a terapia quelante demonstrou boa eficácia neste caso, levando a controle dos sinais e sintomas de intoxicação e promovendo a excreção do chumbo, evidenciada por queda do nível sérico, além da queda nos níveis de ALA-U nos meses seguintes ao tratamento.

Conforme dados fornecidos pelo TOXCENES por e-mail, o único caso de intoxicação pelo chumbo notificado ao serviço em 2018 foi o deste paciente, e não houve registro anterior desde o ano de 2015, o que demonstra a raridade do caso ou possíveis subdiagnóstico e subnotificação.

\section{CONCLUSÃO}

O presente caso clínico releva a importância da intoxicação por chumbo como diagnóstico diferencial para quadros de dor abdominal em unidades de emergência. Casos de intoxicação pelo chumbo podem muitas vezes gerar sinais e sintomas inespecíficos como anemia (fraqueza e fadiga), anorexia, vômitos, constipação, dor abdominal e hipertensão. Portanto, se torna imprescindível a 
educação dos profissionais de saúde acerca do pacientes com quadro clínico semelhante.

tema, para correto diagnóstico e manejo dos

\section{REFERÊNCIAS}

Marginean CO, Melit LE, Moldovan H, Lupu VV, Marginean MO. Lead poisoning in a 16-year-old girl: a case report and a review of the literature (CARE compliant). Medicine. 2016; 95: 38-41.

Dignam T, Kaufmann RB, LeStourgeon L, Brown MJ. Control of Lead Sources in the United States, 1970-2017: Public Health Progress and Current Challenges to Eliminating Lead Exposure. Journal of public health management \& practice. 2019; 25(1): S13-S22.

Madureira PR, Capitani EM, Vieira RJ, Sakuma AM, Toledo AS, Mello SM.

Lead poisoning due to gunshot bullet in contact with cerebrospinal fluid: case report. São Paulo Med Journal. 2009; 127(1):52-4.

Madureira PR, Capitani EM, Vieira RJ. Lead poisoning after gunshot wound. São Paulo Med Journal. 2000; 118(3): 78-80. 